\title{
Explanatory Indispensability Arguments in Metaethics and Philosophy of Mathematics
}

\author{
Debbie Roberts
}

My aim in this chapter is to defend explanatory indispensability arguments for the existence of irreducibly evaluative properties from what I call the supervenience objection. A structurally similar argument and objection are found in the philosophy of mathematics. My strategy is to argue that a response to the supervenience objection is available that is structurally similar to a recent response made in the philosophy of mathematics case. My claim is that reductive realists in metaethics, like nominalists in philosophy of mathematics, have to take what has been called the 'hard road'. And in metaethics, like in philosophy of mathematics, we have good reasons to think that this road is not navigable.

I proceed as follows: Section 10.1 deals with some preliminary background issues. In Section 10.2 I outline the structure of explanatory indispensability arguments in general before giving some cases from metaethics and philosophy of mathematics. In this section I also make some remarks about good explanations and consider and respond to a proto-version of the supervenience objection. I then turn, in Section 10.3, to the supervenience objection itself, and the structurally similar objection in philosophy of mathematics, which I call the nominalist objection. In Section 10.4 I give my response to the supervenience objection, drawing on a recent response Mark Colyvan has made to the nominalist objection.

\subsection{Preliminary Issues}

\subsubsection{Causal v. non-causal explanations}

Historically, it has mostly been naturalist realists who have made appeals to explanatory considerations in metaethical arguments for realism. Moreover, 
these realists have tended to argue that the relevant sort of explanation is causal: moral properties are causally efficacious (or causally relevant) and thus suited to scientific explanation and admissible into our ontology. ${ }^{1}$ Much of the debate has involved responses to Gilbert Harman's claim that moral properties fail to pass an explanatory indispensability test, understood as a test for causal efficacy, where passing this test is necessary for inclusion in our ontology. ${ }^{2}$

Although my focus is on explanation, I am going to depart from the line pursued by naturalist realists in two ways. First, my focus will be evaluative explanation more generally, of which I take moral explanation to be a subset. Second, I am going to be using explanatory considerations to defend a brand of non-reductive realism that resembles in some respects what others have been happy to call non-naturalism. ${ }^{3}$ This will strike some as immediately extremely controversial, and perhaps dubious, because historically non-naturalist realists have not used explanatory indispensability arguments precisely because the relevant sort of explanation was assumed to be causal and non-natural properties are commonly thought to be causally inefficacious. However (and these are further ways in which my argument departs from that pursued by naturalist realists) I am going to bracket the issue of whether the relevant sort of explanation here is causal and the explanatory indispensability argument I am concerned to defend is not intended as a direct response to Harman's challenge. ${ }^{4}$ These last two points are connected, and require some further discussion.

Dialectically speaking, the discussion in this chapter is not best viewed as a continuation of the moral explanation debate started by Harman. Harman's challenge concerns a necessary condition, best interpreted as the claim that an entity or property in question must be causally efficacious to be granted ontological legitimacy. ${ }^{5}$ The argument that I am concerned to defend, on the other hand, takes explanatory indispensability to be a sufficient condition for ontological legitimacy. Moreover, as I said above, I also wish to bracket the issue of whether the relevant sort of explanation is causal. One might think that

\footnotetext{
1 For example, Sturgeon (1986), Brink (1989), Majors (2003). Nelson (2006) makes use of Jackson and Pettit's (1990) notion of program explanation in defending the causal relevance of moral properties.

${ }^{2}$ Harman (1977). See also his (1986) and (1998).

${ }^{3} \mathrm{I}$ put the point in this way because I think the natural/non-natural distinction is problematic. See Dancy (2006 p. 122) and Vayrynen (2009 §3).

${ }^{4}$ I take it that Sturgeon (1992) and Railton (1998) successfully show that the final version of Harman's challenge, that moral theories face a confirmation problem, is at odds with Harman's own moral theory.

${ }^{5}$ See Majors (2007) for a useful overview of the literature in this debate, and a discussion of how the debate concerns particularly the causal-explanatory role of moral properties.
} 
bracketing whether the relevant sort of explanation is causal is a bit of a cheat. I do acknowledge that the question of what kind of explanation this is supposed to be, and why it is ontologically committing, is an important one. For this reason, some of what I say in the later sections is intended to address this issue. But there are a few reasons why it is legitimate to officially bracket this issue here. For one thing, the objection that I am responding to already grants that the relevant explanations are the best ones. Whether these explanations are causal, or must be causal to be the best, is not at issue. For another, the view that explanations must be causal to be appropriately ontologically committing is no longer as widely accepted. ${ }^{6}$

\subsubsection{Appeals to analogies with philosophy of mathematics}

Many prominent non-reductive realists in metaethics are what Sarah McGrath has recently called 'relaxed realists'. 'They hold that whilst moral properties are not causally efficacious, and thus do not pass Harman's explanatory indispensability test, it is a mistake to think that moral properties are thereby metaphysically or epistemically problematic. These realists often appeal to an analogy with mathematical properties to defend their view, where the strategy is one of companions in innocence: roughly the line is that mathematical properties are not causally efficacious, but we are not worried about their metaphysical status or our epistemic access to them, so we should not worry about moral properties in these ways either. ${ }^{8}$

I agree with McGrath that non-reductive realists ought not to be relaxed, and ought to be facing head on what look to be metaphysical and epistemic problems for their view. ${ }^{9}$ And, like McGrath, I think that appeal to the analogy with mathematical properties is in some respects problematic. Platonists in philosophy of mathematics tend not to be relaxed realists at all, but to work very hard to defend the metaphysical and epistemic respectability of mathematical properties.

\footnotetext{
${ }^{6}$ See, for example, Rosen (2010), Lange (2009), Woodward (2003), Strevens (2008), Skow (2013). That the mathematical explanations that I discuss below are not causal but yet are ontologically committing is explicitly accepted by Platonists. And indeed, Platonists make the point that to insist that the explanations be causal to be ontologically committing is to beg the question in this context. It seems at least possible that the explanations in the evaluative case could be noncausal but yet ontologically committing. I leave this issue open though, for even if it turns out that the explanations are causal in the evaluative case this does not, in my view, rule out non-naturalism. See, for example, Wedgwood (2007 pp. 192-9).

7 McGrath (2014 pp. 186-7).

${ }^{8}$ See, for example, Parfit (2011), Scanlon (2014). McGrath's main focus is Dworkin (2011).

9 See, for example, Enoch (2011) particularly chapters 6 and 7. Enoch is suspicious of explanatory indispensability arguments for robust (non-reductive, non-naturalist) moral realism however, though he does not spell out his reasons for this suspicion in detail (2011 p. 53).
} 
At the end of her paper, McGrath expresses a hope that the moral realist will be able to find support for her views in the example of mathematics. One of the respects that she suggests this might be possible concerns explanation. In this chapter my aim is to show that McGrath is correct about this: careful scrutiny of Platonist work in this area can indeed support moral realism, and robust, nonreductive moral realism at that.

\subsection{Explanatory Indispensability Arguments}

The general form of the argument that I am interested in defending is as follows:

(1) A property $E$ or entity $M$ is genuine if reference to that property or entity figures ineliminably in the best explanation of some phenomenon $P .^{10}$

(2) Reference to $E / M$ is indispensable to the best explanation of $P .{ }^{11}$

Hence

(3) $E / M$ is a genuine property/entity.

$E$ is an irreducibly evaluative property and $M$ a mathematical entity.

\subsubsection{Metaethics}

Consider the following cases:

Donald is rude. Suppose that Donald behaves rudely. He shouts 'This is utter rubbish', loudly, in the middle of a visiting speaker's talk. The other members of the audience become embarrassed and annoyed with Donald. ${ }^{12}$ What explains the audience's embarrassment and annoyance? Plausibly, Donald being rude.

Growth of political protest movements. The growth of political protest movements and social instability is to be explained by the injustice of the society. ${ }^{13}$

The cowardly rescuer. The fact that the leader of the rescue expedition was vain and cowardly explains the incompetence of that expedition, and thus the numbers of people that perished. ${ }^{14}$

${ }^{10}$ I take it that this is a sufficient, but not necessary, condition for genuineness.

${ }^{11}$ For ease of phrasing, I'm here assuming that reference without referents is possible. But nothing hangs on this, and the premise could be phrased to eliminate talk of reference.

12 Adapted from Harman \& Thomson (1996 pp. 81-3) cited in Wedgwood (2007 p. 194).

13 This example is common in the literature on moral explanation. An early statement can be found in Brink (1989 pp. 190-4) cited in Sinclair (2011 p. 2).

14 Sturgeon (1985 p. 63). 
Systematic lack of self-esteem. Widespread lack of self-esteem in members of certain groups in a society can be explained by degrading (for example, racist or sexist) socio-political structures that systematically undermine the perceived worth of members of these groups. ${ }^{15}$

Many more examples of this sort could be given. Such cases can figure in explanatory indispensability arguments for non-reductive realism in metaethics. These arguments claim that the moral or evaluative property (more precisely, reference to such a property) is indispensible to the best explanation of the phenomena to be explained, and that this commits us to the existence of irreducibly evaluative properties. ${ }^{16}$

\subsubsection{Philosophy of mathematics}

In order to see why current work on explanatory indispensability arguments in philosophy of mathematics may be helpful to metaethicists, it will be useful to first fill in some background before looking at examples of such arguments in more detail.

Historically, the most influential indispensability argument in the philosophy of mathematics is the Quine-Putman Indispensability Argument which can be represented as follows:

(P1) We ought to have ontological commitment to all and only the posited entities that are indispensable to our best scientific theories.

(P2) Mathematical posits are indispensable to our best scientific theories.

Hence

(C) We ought to have ontological commitment to mathematical entities.

This argument is not specifically an explanatory indispensability argument. Exactly what mathematical posits are indispensable for will depend on the criteria for good scientific theories. Explanatory power will be only one of those; unificatory power and simplicity may be others. As it stands, 'indispensable for science' could allow mathematical posits into the ontological fold without those posits having to do any explanatory work at all. Moreover, Quinean holism, understood as the picture of science as a web of interconnected theories evaluated

15 See, for example, Rawls (1971 part III) and Dillon (1997).

16 In the cases above, I use thick concepts and properties as examples of evaluative concepts and properties. This is not uncontroversial, but for the purposes of this chapter I am going to assume that thick concepts and properties are inherently evaluative. 
as a single whole by balancing the criteria for good scientific theories, makes it even easier for Platonists: if the best web contains mathematical posits, then the entities posited are indispensable for science no matter where in the web those posits appear.

We might worry that this makes things too easy, that a posit merely appearing somewhere in a web of scientific theories is not sufficient to warrant ontological commitment to the entities referred to by that posit. Those who feel the force of this worry think that since inference to the best explanation is the major generator of ontological commitment within scientific realism, the way to make things tougher here is to require that mathematic posits must be indispensable for explanatory purposes. Moreover, to avoid mathematical entities riding in on the coat-tails of the entities actually doing the real explanatory work, Platonists have lately come to argue for the existence of mathematical entities by focusing on their indispensability in individual explanations of specific phenomena. ${ }^{17}$

On the face of it, though, there are certain affinities between Platonism in philosophy of mathematics and non-reductive realism of the sort that I am interested in defending-both claim the existence of entities or properties that are held to be metaphysically queer and epistemically inaccessible in similar sorts of ways. A potentially fruitful way for the non-reductive realist to proceed then is to explore this more recent work on explanatory indispensability in philosophy of mathematics. Here are two examples of such arguments:

Periodical Cicadas. The best explanation of why periodical cicadas have the life-cycle periods that they do is that prime periods are evolutionarily advantageous. This is because having a life-cycle period that minimizes intersection with other (nearby/lower) periods is evolutionarily advantageous. ${ }^{18}$

Throwing Sticks. Suppose that you throw some sticks into the air with a lot of spin, so that they separate and tumble about as they fall. Freeze the scene at some point during the sticks' descent. Why are more of them near the horizontal axis than near the vertical rather than in more or less equal numbers at each orientation? The best explanation of this fact appeals to geometric facts. Roughly speaking, there are many more ways for a stick to be near the horizontal than near the vertical. ${ }^{19}$

17 See, for example, Baker (2005). $\quad{ }^{18}$ Baker (2005 p. 233).

19 Lipton (1991 pp. 33-4) cited in McGrath (2014 pp. 190-1). 


\subsubsection{Good explanations}

At this point, it is helpful to note the following about good explanations. ${ }^{20}$ Good explanations have explanatory power. This involves at least two things. The first is the capacity to discriminate. A good explanation must discriminate between all the features present in a case, picking out only some, the ones that plausibly do the explanatory work. The second is a capacity to generalize. Whatever features are picked out as doing the explanatory work, these must be ones that will also do the same explanatory work across a range of relevantly similar situations. These two features are connected. If the explanation has the capacity to generalize across the relevant range of situations, that increases the plausibility that the explanation discriminates in the right sort of way, that is, by picking out those features that actually do the explanatory work.

For (reference to) a property or entity to be indispensable to a good explanation is for it to be the case that it could not be eliminated from the explanation without making that explanation worse. Explanations are made worse if they are made to lack the capacities to generalize and to discriminate. To illustrate these points, consider the following.

In principle, it might be possible to come up with an explanation in the throwing sticks case that makes no reference to geometric facts but only to the physical forces that each stick is subject to. This explanation discriminates as it picks out only some features of the case, namely the physical forces that each stick is subject to. It is plausible that the physical forces explain in this case since conjoining all of the physical explanations for each individual stick would result in a sufficient condition for the sticks being in the position that they are when the scene is frozen.

However, this explanation has no capacity to generalize in the appropriate way, and this undermines the plausibility that this explanation discriminates in the appropriate way. Consider that if we were to vary certain elements of the case, for example, the position of your hands when you released the sticks, the force with which you threw them into the air, the precise amount of spin, and the precise point at which the scene is frozen, it would still be the case that more of the sticks would end up near the horizontal axis than near the vertical at the point at which the scene is frozen. Intuitively, these are elements of the case that are not essential to the explanandum. However, the long conjunction of physical

\footnotetext{
${ }^{20}$ Note that my aim is not to give a list of necessary and sufficient conditions for good explanations. I pick on only two features here which are plausibly both necessary. This is not meant as an exhaustive account of good explanations.
} 
explanations for the movement of each stick in the original case would not be able to explain the position of the sticks in any of these new cases. ${ }^{21}$ This means that the long conjunction fails to generalize across the relevant range of situations.

By contrast, the explanation that makes reference to geometric facts both discriminates and has the capacity to generalize: this explanation can explain the original case, and any of the subsequent cases generated by varying any or all of the non-essential elements of the explanandum. This increases the plausibility of the claim that this explanation discriminates in the appropriate way, that is, that the right facts are being picked out as explanatory.

Accordingly, reference to geometric facts could not be eliminated from the explanation in the throwing sticks case without making for a worse explanation. Since we are licensed to accept into our ontology entities the reference to which is indispensible to the best explanation of specific phenomena, we are licensed to accept the existence of geometric facts. ${ }^{22}$

Return now to the evaluative cases:

Donald is rude. Suppose that Donald behaves rudely. He shouts 'This is utter rubbish' in the middle of a visiting speaker's talk. The other members of the audience become embarrassed and annoyed with Donald. What explains the audience's embarrassment and annoyance? Plausibly, Donald being rude.

Growth of political protest movements. The growth of political protest movements and social instability is to be explained by the injustice of the society.

The cowardly rescuer. The fact that the leader of the rescue expedition was vain and cowardly explains the incompetence of that expedition, and thus the numbers of people that perished.

Systematic lack of self-esteem. Widespread lack of self-esteem in members of certain groups in a society can be explained by unjust (for example, racist or sexist) socio-political structures that systematically undermine the perceived or felt worth of members of these groups.

Using such cases, non-reductive realists in metaethics can argue for ontological commitment to irreducibly evaluative properties, if it is the case that reference to the irreducibly evaluative property could not be removed without making the explanation worse.

One immediate stumbling block for the non-reductive realist concerns the supervenience of the evaluative on the non-evaluative. Explanatory indispensability

21 See also McGrath (2014 pp. 190-1).

${ }^{22}$ For a detailed and persuasive argument for the claim that the cicada case gives us a genuine mathematical explanation of a physical phenomenon see Baker (2005). 
arguments for irreducibly evaluative properties seem open to the objection that in each case it is not the evaluative property that does the genuine explanatory work, but the underlying non-evaluative properties. In the rudeness case, one might object, it is not rudeness that explains the audience's embarrassment and annoyance, but the non-evaluative properties of Donald's action.

However, given the multiple realizability of evaluative properties, this protosupervenience objection fails. And it fails for the same reason that the physical forces explanation in the throwing sticks case fails, namely that replacing reference to rudeness with Donald's actions non-evaluatively described fails to generalize in the appropriate sort of way. We could vary certain elements (for example, the precise words Donald uttered, replacing his words with gestures) and get the same result, namely that the audience is embarrassed and annoyed. 'That Donald was rude' is explanatory in these new cases, whereas the nonevaluative description of Donald's action in the first case would not be. ${ }^{23}$

There is, however, a more pressing supervenience objection which might be levelled against the non-reductivist. This objection is analogous to one that certain nominalists have made in philosophy of mathematics.

\subsection{The Objection}

The general form of the objection I am here concerned to respond to is as follows:

(2) Reference to $E / M$ is indispensible to the best explanation of $P$.

(4) Even if reference to $E / M$ is indispensable to the best explanation of $\mathrm{P}$, this does not generate ontological commitment to $E / M^{24}$

I will call the objection as it arises in metaethics the supervenience objection and as it arises in philosophy of mathematics the nominalist objection. There are of course a number of objections that can be made to explanatory indispensability arguments, both in general and to the particular version I am interested in defending. My aim here is limited to defending explanatory indispensability arguments for the existence of irreducibly evaluative properties from the supervenience objection.

But there is another possible objection worth mentioning at this point, for it might mistakenly be conflated with the supervenience objection. In response to

\footnotetext{
${ }^{23}$ Wedgwood defends a similar response (2007 pp. 193-7). Reductivists may deny the multiple realizability of evaluative properties. I consider this response in Section 10.4.2.

${ }^{24}$ (4) is of course the negation of (1).
} 
the above cases, it may be claimed that reductive analyses of thick concepts and the terms that express them are available. To take the cowardly rescuer case, such a response would claim that 'cowardice' can be reduced to a certain evaluatively neutral character trait (a certain attitude to fear, say) to which is attached a negative evaluation. Those tempted by such reductive accounts will go on to claim that what does the explanatory work in the cowardly rescuer case is the evaluatively neutral character trait, and not the attached negative evaluation. Call this the reductive analysis objection.

This reductive analysis objection is a different objection from the supervenience objection for it denies what the supervenience objection accepts, namely that evaluative terms are indispensible to the best explanations of some phenomena. According to the reductive analysis objection, we can replace reference to cowardice in the cowardly rescuer case with reference to the relevant evaluatively neutrally specified character trait, and incur no explanatory loss.

In my view, reductive analyses of thick concepts and the terms that express them are not available. However, given the aim of this chapter, this is not something that I will argue for here. ${ }^{25}$

Before I outline the supervenience objection in more detail, it is helpful to examine the nominalist objection in the philosophy of mathematics.

\subsubsection{Philosophy of mathematics: the nominalist objection}

In opposition to Platonists, nominalists in the philosophy of mathematics deny the existence of mind-independent, abstract mathematical objects. They thus deny that explanatory indispensability arguments like the ones referred to in Section 10.2 succeed in establishing the ontological credentials of mathematical entities. In response to these arguments, some nominalists pursue the kind of strategy outlined in the objection above. That is, these nominalists argue for (4): that even if mathematical terms are indispensable to the best explanation of some specific phenomenon, this does not generate ontological commitment to mathematical entities. ${ }^{26}$

${ }^{25}$ One might, however, take the view that reductive analyses of thick terms and concepts are not available but that nonetheless a reductive account of the thick property is available. On this view, thick terms-but not thick properties-would be indispensible to the best explanations of some phenomena. The response I offer in this chapter will be directed against such views insofar as they make use of supervenience in providing the reduction of the thick property.

${ }^{26}$ This claim, or something very close to it, is endorsed by all those who wish to remain scientific realists and to retain commitment to electrons and other theoretical entities, and who accept that mathematics has an essential role to play in science. See, for example, Azzouni (2004), Leng (2010), (2012), Melia (2000), Yablo (1998) cited in Colyvan (2010). 
To use Mark Colyvan's terminology these are nominalists who think there is an 'easy road' to nominalism, as opposed to the 'hard road' attempted by Field. ${ }^{27}$ The hard road to nominalism in philosophy of mathematics is that which requires the nominalizing empirical science. This approach denies (2). Denying (2) requires showing that our best scientific theories can be rewritten without any of the mathematics. This is widely acknowledged to be an extremely difficult task. $^{28}$ Because of this, nominalists have been tempted down the easier road of defending (4). ${ }^{29}$

These nominalists recognize the immense value of mathematics in formulating scientific theories. Indeed, they are happy to say that mathematics plays an indispensable descriptive/representational/expressive/accessing role-it is the only way we have to describe/represent/express/access the nominalistic content of empirical science. However, they argue, such indispensability fails to generate ontological commitment to mathematical entities. In Joseph Melia's terms, mathematics in science is necessary only to make certain things sayable about concrete objects; mathematical entities do not actually exist though, for mathematized theory is simply a way of representing the non-mathematical world. ${ }^{30}$ In Mary Leng's terms, mathematical posits are fictions playing an indispensable representational/descriptive role, but fictions nonetheless. ${ }^{31}$

\subsubsection{Metaethics: the supervenience objection}

It might seem that the proponent of the explanatory indispensability in metaethics is even more vulnerable to this kind of objection than the Platonist. Many, if not all, metaethicists-including non-reductive realists-endorse a global supervenience thesis along the following lines:

For all worlds $w$ and $w^{*}$, if $w$ and $w^{*}$ are exactly alike non-evaluatively then they are exactly alike evaluatively. ${ }^{32}$

This supervenience claim can be used to generate the analogous objection. This version of the objection makes use of Jackson's supervenience argument for his analytical descriptivism. ${ }^{33}$ This argument is as follows.

\footnotetext{
27 Colyvan (2010). $\quad{ }^{28}$ See Burgess and Rosen (1997) cited in Colyvan (2010).

${ }^{29}$ Colyvan (2010 pp. 285-6). $\quad{ }^{30}$ Melia (2000 p. 455). ${ }^{31}$ Leng (2012 p. 2).

32 Exactly how this thesis should be formulated is a contentious issue. In particular, whether the base properties should be characterized as 'non-evaluative' or 'natural' or 'descriptive' is a matter of controversy. In my view this formulation is the least controversial. See Roberts (2011).

33 Jackson (1998 Ch. 5). Jackson himself doesn't use his supervenience argument to make this objection to the explanatory indispensability argument.
} 
Start from the representative evaluative predicate E 'is a rude action' together with an action that satisfies that predicate. There will be a complete, nonevaluative, description of that action and the world in which it occurs, given by an enormous descriptive predicate $D_{1}$. Given the supervenience thesis, $D_{1}$ entails E. But $\mathrm{E}$ doesn't entail $\mathrm{D}_{1}$, for there may be other, different actions, characterized non-evaluatively, that also count as rude. However, each of the actions-in-worlds which satisfy E-there is a possibly infinite number of these-will have a nonevaluative description; $D_{2}, D_{3}, D_{4} \ldots D_{n}$. The disjunction of all these nonevaluative descriptions is $\mathrm{D}^{\star}$. Now $\mathrm{E}$ entails $\mathrm{D}^{\star}$ but $\mathrm{D}^{\star}$ also entails $\mathrm{E}$. Indeed, $E$ is necessarily equivalent to $D^{*}$. Jackson claims then that since necessarily equivalent predicates pick out the same property, we ought to conclude that E picks out the non-evaluative property picked out by $\mathrm{D}^{*}{ }^{34}$

We can run this same argument for any evaluative predicate. However, as Jackson notes, it does not follow from the necessary equivalence of $\mathrm{E}$ and $\mathrm{D}^{*}$ that ethical vocabulary is dispensable in practice. Since $\mathrm{D}^{\star}$ is an enormous, potentially infinite disjunction, we will still need to use evaluative predicates. ${ }^{35}$ Indeed, we can say that our evaluative predicates will be an incredibly useful, even indispensable, way of describing/representing/expressing/accessing the underlying non-evaluative features. However, given the supervenience argument, despite the indispensability of ethical terms, we can conclude that there is nothing more there in the world, there are no extra features over and above the nonevaluative features.

This argument can be used to generate the supervenience objection, analogous to the nominalist objection outlined above. To reiterate, these objections grant that the relevant terms can be explanatorily indispensible, but deny that this generates ontological commitment to the entities or properties in question. ${ }^{36}$ According to the supervenience objection, evaluative predicates like 'is a rude action' are merely a distinctive way of representing a purely non-evaluative realm. Even if the evaluative predicate figures indispensably in the best explanation of some phenomenon, what it picks out in the world, given supervenience,

\footnotetext{
34 Jackson (1998 pp. 122-4). $\quad{ }^{35}$ Jackson (1998 p. 124).
}

36 One potential disanalogy here. Mathematical nominalists typically take it that since there are no mathematical entities to which mathematical terms refer, the application of such terms typically results in false claims, literally interpreted. Their point is that this is no bar to such terms being explanatorily indispensible (they are useful fictions). The proponent of the supervenience objection in metaethics, however, grants that applications of moral terms can state truths. Their point is that these truths can be reduced truths about non-evaluative properties. But crucially for the current argument, both views condone the use of the disputed terms and allow that this use can be indispensible in explanatory contexts whilst denying that such use incurs the relevant ontological commitment. 
is a non-evaluative property $\left(\mathrm{D}^{*}\right)$. We ought to conclude that explanatory indispensability does not generate ontological commitment to irreducibly evaluative properties.

\subsection{Reply}

The general strategy of my reply I borrow from one recently pursued by Mark Colyvan against easy-road nominalists. ${ }^{37}$ This strategy is to argue that the easy road is not available. More specifically, this is to argue that claim (4) is not defensible. This means that those who want to avoid ontological commitment to the properties or entities under discussion cannot claim (2). In other words, they have to take the hard road of demonstrating how the relevant terms can be dispensed without explanatory loss.

The nominalists in philosophy of mathematics I discuss here are scientific realists who accept inference to the best explanation (IBE) as a generator of ontological commitments. Likewise, I take the reductive realists who are my opponents here not to dispute the legitimacy of IBE in general. This point is important to the argument below.

\subsubsection{Philosophy of mathematics: the content challenge}

Colyvan's response to easy-road nominalists is as follows: Since easy-road nominalists are scientific realists, and not sceptical of IBE in general, an independently motivated account is needed of why we do not get ontological commitment from mathematical explanatory indispensability arguments. However, claims Colyvan, this independently motivated account of why some cases of indispensability are ontologically committing and some are not is not to be found. Instead, what we find is that the accounts given trade on nominalist intuitions that mathematical entities have no ontologically committing role to play. This is really no more than a hunch that total theory will in fact tell us that mathematical entities are not required. To make good on this hunch, Colyvan concludes, those who would do without admitting mathematical entities to our ontology have to show that mathematics is in fact dispensable to science. In other words, they have to embark down Field's hard road, a road widely regarded as highly unlikely to lead to success.

As an illustration of the above, consider Joseph Melia's 'weasel nominalism', the strategy of retracting what you have previously said. ${ }^{38}$ Melia argues, contra Putnam, that it is not inconsistent or intellectually dishonest to quantify over

$$
37 \text { Colyvan (2010). } \quad{ }^{38} \text { Melia (2000). }
$$


mathematical objects yet deny the existence of such objects. He points out that often we say things that are contradictory only on an uncharitable understanding, such as 'All Fs are Gs except b'. This is not a contradiction but a weasely retraction. Charitably, we should understand this as 'all Fs except b are G'. Similarly, Melia argues, when a nominalist says something like 'the life cycles of periodical cicadas are always prime but there are no primes' we ought not to understand this as contradictory. Just as we are allowed to add details to the story about the world that were omitted earlier, so we should be allowed to take back details that were included earlier. Moreover, sometimes, says Melia, the only way we can say what we want to say is by weaselling. ${ }^{39}$ The use of mathematical talk in science is a case in point. This shouldn't concern us, however, because weaselling is a legitimate strategy.

We can grant for the sake of argument that weaselling is sometimes a legitimate strategy. However, it cannot always be legitimate, of course. ${ }^{40}$ We can change the story we are telling by adding or subtracting minor details, but we cannot be thought to be telling a consistent story or any story at all if we retract too much. As Colyvan points out, Tolkien could not, late in the Lord of the Rings trilogy, take back all mention of hobbits, for they are too central to the story. If he were to do this we would be correct in demanding a paraphrase of the hobbitless story so far, for without this we would be lost as to what the story was supposed to be. We lose a grip on what is being said if too much is retracted.

The crucial question is what counts as too much? The answer seems to depend on the availability of a suitable paraphrase. In the example given above, the appearance of contradiction is merely that only because there is a paraphrase available that explains this appearance away: all Fs, except b, are Gs. Consider, though, cases of sentences where there is no available non-obvious paraphrase, let alone an obvious one, and where those sentences are indispensable to the story we are telling. Given that there is no background wholesale rejection of explanatory indispensability arguments, what reason is there for weaselling and not taking the relevant sentences to be ontologically committing? The thought must be that it is really something else, not primeness, that is doing the explanatory work. The only 'reason' in the vicinity then, argues Colyvan, is an appeal to prior nominalist intuitions and sympathies-a hunch that there are not really any mathematical entities in the world which could be doing any explanatory work.

Now, obviously, such a move begs the question against the Platonist. It is true that non-existent entities cannot enter into true explanations, but we have not yet

39 Melia (2000 pp. 468-70).

40 My discussion of Melia's argument follows Colyvan (2010 pp. 294-7). 
been given any reason to think that these entities are non-existent. Dialectically speaking, what is really required at this point is that the nominalist provide the paraphrase which explains away the apparent contradiction generated by weaselling. Colyvan's challenge is this: what is the nominalistic content that such sentences describe/access/express/represent? This content challenge is the challenge of giving up the easy road and embarking down the hard road of nominalizing science. And this road is widely regarded as extremely difficult, likely impossible, to navigate.

\subsubsection{Metaethics: the reduction challenge}

Return now to the supervenience objection. The non-reductivist can pursue Colyvan's line, and ask for the independently motivated account of why good evaluative explanations are not ontologically committing. In the end, I think, such an account is not forthcoming here either, though the appeal to supervenience means that we must go through more steps to see why this is so.

Take the Donald case above. Suppose the reductive realist says that what best explains the audience's embarrassment and annoyance is that Donald was rude, but rudeness, the irreducible evaluative property, does not exist; there is no such property doing the genuinely explanatory work. The non-reductivist may now make the request for the independently motivated account of why no ontological commitment to rudeness is generated in this case, despite the indispensability of the term 'rude'. In answer to this request, the reductivist can appeal to global supervenience, which the non-reductivist accepts.

In this, metaethical case, unlike in the mathematical case, it seems as though there is available an in principle way to effect the paraphrase: making use of the global supervenience thesis, the supervenience argument tells us of the necessary presence of $\mathrm{D}^{*}$. It is this-possibly infinite-disjunction of the underlying nonevaluative descriptions of rude actions-in-worlds that is doing the genuine explanatory work, the reductivist can claim. Given the sheer size and complexity of $\mathrm{D}^{*}$ providing the paraphrase is likely not going to be possible for an ordinary human mind. However, it is open to the reductivist to reply that, unlike in the mathematical case, we have something that guarantees that there will be such a translation. Moreover, the reductivist can say, the possibility in principle of such a translation is all we need to defend the plausibility of the claim that terms can be indispensible to explanations without generating ontological commitments to the entities they purport to refer to.

However, it merely appears that the evaluative reductivist is in a better position than the mathematical nominalist. Remember that good explanations must have both the capacity to discriminate and the capacity to generalize. The complexity 
(but in principle availability) of $\mathrm{D}^{*}$, is what is supposed to answer the question of why it is legitimate to claim that evaluative terms can be indispensible to explanations without generating ontological commitment to irreducibly evaluative entities. But it is not at all plausible that $\mathrm{D}^{*}$ explains anything, for $\mathrm{D}^{*}$ fails to discriminate, and it thus fails to generalize in the appropriate way.

Why does it not generalize in the appropriate way? Consider what $\mathrm{D}^{*}$ is: a potentially infinite disjunction where each disjunct is a complete non-evaluative description of an action and the entire world in which it is situated. It is true that wherever we have a rude action we will have $\mathrm{D}^{*}$ because one of the disjuncts of $\mathrm{D}^{\star}$ will be instantiated. In that sense there is a guarantee, and $\mathrm{D}^{*}$ will apply across a range of different situations. But this guarantee is in no sense explanatory, and thus what generalizes is not the explanation. This guarantee is not explanatory for most of what each disjunct of $\mathrm{D}^{\star}$ contains is irrelevant. Each disjunct of $\mathrm{D}^{\star}$ fails to discriminate between those features that are doing explanatory work and those that are not. ${ }^{41}$ Citing $\mathrm{D}^{\star}$ as explanatory in this case would be like citing as explanatory a potentially infinite disjunction of complete physical descriptions of actions in entire worlds in the throwing sticks case. This would fail to even pick out the physical forces each stick is subject to as especially explanatorily relevant.

Analogous to the situation of the easy-road nominalist, then, it turns out that the reductivist cannot claim that although evaluative terms are indispensible to the best explanations of certain phenomena this in no way commits us to the existence of irreducibly evaluative properties. And this remains so even though in the metaethical case there is available the appeal to the global supervenience thesis which is accepted on both sides. Given the dialectical situation, the burden of proof is on the reductivist to provide the account of which of the non-evaluative features in each disjunct of $D^{\star}$ are explanatory. Moreover, the reductivist also has to ensure that the explanations provided generalize appropriately.

In other words, what the reductivist has to do is actually provide the reductive account.

It may seem at this point as if the road the reductivist has to take in metaethics is not as hard as the analogous road that the nominalist has to take in philosophy of mathematics. The reductivist can appeal to an argument Jackson, Smith, and Petit level against particularism in ethics. ${ }^{42}$ Their argument is semantic and proceeds as follows:

\footnotetext{
${ }^{41}$ Dancy (2004) makes a related point, in objecting to Jackson's argument, concerning rightmakers and the right-making relation.

42 Jackson, Petit, and Smith (2000).
} 
We use words to mark divisions in the world, tables are different from chairs, and rude acts are different from tactful ones. What marks rude acts off from tactful acts must be something that all the rude acts have in common. Grasp of the predicate 'is a rude action' simply consists in grasping the various disjuncts of $\mathrm{D}^{*}$. But that can't be all that unites the class of rude actions. There must be some commonality or pattern that we cotton on to and that allows projection from some sub-set of the disjuncts of $\mathrm{D}^{*}$ to new members. If there weren't such a commonality then we finite creatures could not have grasped the predicate 'is a rude action'.

The reductivist can go on to claim that this commonality is what is explanatory in the Donald case. It is this feature, or set of features, that does the explanatory work and, what's more, this generalizes appropriately across the relevant range of cases where rude actions cause embarrassment and annoyance.

The trouble with this argument is that it relies on an appeal to prior reductivist intuitions and sympathies. Jackson, Pettit, and Smith assume that the commonality will be a set of non-evaluative features. ${ }^{43}$ But this assumption is in no way warranted. For the commonality or pattern need not be nonevaluative. The commonality may obtain only at the evaluative level. Apart from some antecedent commitment to reductivism, why should we accept that the commonality doing the genuine explanatory work in the evaluative case exists at the non-evaluative level? If the commonality exists only at the evaluative level, then the only explanation available here which has the appropriate capacity to generalize will be the one that makes reference to the evaluative property. To put it in McDowell's terms, the aspect of the world which prompts the value judgment may not be, even in principle, recognizable as the aspect it is independently of evaluation. ${ }^{44}$

The upshot of this is that the supervenience objection to the evaluative indispensability argument fails. Just as it is not legitimate for the nominalist to allow the explanatory indispensability of mathematical terms whilst denying that this generates ontological commitment to mathematical entities, so it is not legitimate for the reductive realist to allow the explanatory indispensability of evaluative terms whilst denying ontological commitment to irreducibly evaluative properties. The mathematical nominalist must provide the mathematicsfree translation of mathematical explanations in science, without explanatory loss, and the reductivist must make the evaluative distinctions in the world in non-evaluative terms, without explanatory loss.

\footnotetext{
43 This is to deny the multiple realizability of evaluative properties.

44 McDowell (1998 pp. 201-2).
} 
I have already mentioned that the road facing the nominalist is widely regarded as so difficult as to be impassable. What reasons do we have to think that the road for the evaluative reductivist will be similarly difficult? That the reductivist must make the evaluative divisions in the world in non-evaluative terms can be understood as a request for a complete mapping of evaluative features on to non-evaluative features: 'If objects have natural features $N$ then they have evaluative features $E$, 'If objects have natural features $N^{\star}$ then they have evaluative features $E^{\star}$, and so on. ${ }^{45}$ What this is, on one influential way of thinking about normative ethical theories, is a request for the true normative ethical theory. And apart from some antecedent commitment to reductivism, why should we think that this is possible?

\section{References}

Azzouni, J. 2004. Deflating Existential Consequence: A Case for Nominalism. New York: Oxford University Press.

Baker, A. 2005. 'Are there Genuine Mathematical Explanations of Physical Phenomena?'. Mind 114(454): 223-38.

Brink, D. 1989. Moral Realism and the Foundations of Ethics. Cambridge: Cambridge University Press.

Burgess, J. and Rosen, G. 1997. A Subject with No Object: Strategies for Nominalistic Interpretation of Mathematics. Oxford: Oxford University Press.

Colyvan, M. 2010. 'There is No Easy Road to Nominalism'. Mind 119(474): 285-306.

Dancy, J. 2004. 'Discussion on the Importance of Making Things Right'. Ratio 17(2): 229-37.

Dancy, J. 2006. 'Nonnaturalism'. In: Copp, D. (ed). The Oxford Handbook of Ethical Theory. New York: Oxford University Press, pp. 122-45.

Dillon, R. 1997. 'Self respect: Moral, Emotional and Political'. Ethics 107(2): 226-49.

Dworkin, R. 2011. Justice for Hedgehogs. Cambridge, MA: Harvard University Press.

Enoch, D. 2011. Taking Morality Seriously. Oxford: Oxford University Press.

Harman, G. 1977. The Nature of Morality. Oxford: Oxford University Press.

Harman, G. 1986. 'Moral Explanations of Natural Facts-Can Moral Claims be Tested against Reality?'. Southern Journal of Philosophy 24 (suppl.): 57-68.

Harman, G. 1998. 'Responses to Critics'. Philosophy and Phenomenological Research 58: 207-14.

Harman, G. and Thomson, J. 1996. Moral Relativism and Moral Objectivity. Oxford: Blackwell.

Jackson, F. 1998. From Metaphysics to Ethics. Oxford: Oxford University Press.

Jackson, F. and Pettit, P. 1990. 'Program Explanation: A General Perspective'. Analysis 50: $107-17$. 
Jackson, F., Pettit, P., and Smith, M. 2000. 'Ethical Particularism and Patterns'. In: Hooker \& Little (eds). Moral Particularism. Oxford: Oxford University Press, pp. 79-99.

Lange, M. 2009. 'A Tale of Two Vectors'. Dialectica 63: 397-431.

Leng, M. 2010. Mathematics and Reality. Oxford: Oxford University Press.

Leng, M. 2012. 'Taking It Easy: A Response to Colyvan'. Mind 121(484): 983-95.

Lipton, P. 1991. Inference to the Best Explanation. London: Routledge.

Majors, B. 2003. 'Moral Explanation and the Special Sciences'. Philosophical Studies 113: $121-52$.

Majors, B. 2007. 'Moral Explanation'. Philosophy Compass 2(1): 1-15.

McDowell, J. 1998. 'Non-Cognitivism and Rule-Following'. In his Mind, Value, Reality. Cambridge, MA: Harvard University Press.

McGrath, S. 2014. 'Relax? Don't Do It! Why Moral Realism Won't Come Cheap'. In: Shafer-Landau, (ed). Oxford Studies in Metaethics 9: 186-214.

Melia, J. 2000. 'Weaseling Away the Indispensability Argument'. Mind 109: 455-79.

Nelson, M. 2006. 'Moral Realism and Program Explanation'. Australasian Journal of Philosophy 84(3): 417-28.

Parfit, D. 2011. On What Matters. Oxford: Oxford University Press.

Railton, P. 1998. 'Moral Explanation and Moral Objectivity'. Philosophy and Phenomenological Research 58: 175-82.

Rawls, J. 1971. A Theory of Justice. Cambridge, MA: Harvard University Press.

Roberts, D. 2011. 'Shapelessness and the Thick'. Ethics 121(3): 489-520.

Rosen, G. 2010. 'Metaphysical Dependence: Grounding and Reduction'. In: Hale and Hoffman (eds). Modality: Metaphysics, Logic, and Epistemology. New York: Oxford University Press, pp. 109-35.

Scanlon, T. 2014. Being Realistic about Reasons. Oxford: Oxford University Press.

Sinclair, N. 2011. 'The Explanationist Argument for Moral Realism'. Canadian Journal of Philosophy 41(1): 1-24.

Skow, B. 2013. 'Are There Non-Causal Explanations (of Particular Events)?'. British Journal for the Philosophy of Science 65: 445-67.

Smith, M. 2004. 'Does the Evaluative Supervene on the Natural?'. In his Ethics and the A priori. New York: Cambridge University Press.

Strevens, M. 2008. Depth: An Account of Scientific Explanation, Cambridge, MA: Harvard University Press.

Sturgeon, N. 1985. 'Moral Explanations'. In: Copp, D. and Zimmerman, D. (eds). Morality, Reason and Truth. Totowa, NJ: Rowman and Allanheld, pp.49-78.

Sturgeon, N. 1986. 'Harman on Moral Explanations of Natural Facts'. Southern Journal of Philosophy 24 (suppl.): 69-78.

Sturgeon, N. 1992. 'Nonmoral Explanations'. Philosophical Perspectives 6: 97-117.

Väyrynen, P. 2009. 'Normative Appeals to the Natural'. Philosophy and Phenomenological Research 79(2): 279-314.

Wedgwood, R. 2007. The Nature of Normativity. Oxford: Oxford University Press.

Woodward, J. 2003. Making Things Happen: A Theory of Causal Explanation. New York: Oxford University Press.

Yablo, S. 1998. 'Does Ontology Rest on a Mistake?'. Aristotelian Society Supplementary Volume 72(1): 229-83. 